\title{
Resilience Model of Crisis Rescuer and Its Training and Development
}

\author{
Shi Kan ${ }^{1,2,}$, Zhao Yiran², He Qin ${ }^{3}$, Liang Shehong ${ }^{4}$ \\ ${ }^{1}$ Wenzhou Model Development Institute \& School of Education, Wenzhou University, China. \\ ${ }^{2}$ Department of Psychology, Renmin University of China, China. \\ ${ }^{3}$ Department of Psychology, University of Illinois at Urbana-Champaign, China. \\ ${ }^{4}$ The Center for Psychological Sciences, Zhejiang University, China.
}

How to cite this paper: Shi Kan, Zhao Yiran, He Qin, Liang Shehong. (2020) Resilience Model of Crisis Rescuer and Its Training and Development. Journal of Humanities, Arts and Social Science, 4(1), 67-78.

DOI: $10.26855 /$ jhass.2020.01.009

Received: April 17, 2020

Accepted: May 26, 2020

Published: June 23, 2020

*Corresponding author: Shi Kan, Wenzhou Model Development Institute \& School of Education, Wenzhou University, China; Department of Psychology, Renmin University of China, China.

Email: shik@psych.ac.cn

\begin{abstract}
As emergencies are uncertain, complex and unpredictable, and especially, sudden public crisis events have extremely destructive effects on our society, crisis management has become an important research project. It is important for government to construct a set of scientific coping mechanisms and enhance the resilience of rescuers. However, there are few studies on the resilience of rescuers in the literature. Focusing on emergency of public crisis, this study was proposed to explore the structure and mechanism of resilience of Chinese rescuers, and their team. Two thousand subjects were involved in total. Through the methods of document analysis, behavior event interview, focus group interview, expert discussion, and questionnaire survey, the current study developed two resilience questionnaires of crisis rescuers and their team respectively. Furthermore, and verified the effectiveness of the following intervention mode methods based on the model of resilience: individualized consultation, experiential scenario, group counseling and cooperative group training, etc. Finally, we provided an effective intervention mode and a national crisis management platform, aiming to improve rescuers' coping style with emergency events, which have significant application values.
\end{abstract}

\section{Keywords}

Emergency, Crisis rescuers, Rescue team, Resilience, Intervention model, Training \& Development

\section{Introduction}

\subsection{The necessity of crisis coping}

At present, the whole world is developing more and more globally and digitally, which makes the already-complex social environment more dynamic and uncertain. Strictly, "crisis events" are highly uncertain, strikingly destructive, unpredictable, obviously complicated, and hard to handled with conventional management methods (Jin, Qu, \&Bao, 2019; Williams, Gruber, Sutcliffe, Shepherd, \& Zhao, 2017). Therefore, they are also called unconventional emergencies. Because they are unpredictable and happen in an abrupt fashion, crisis events often lead to secondary hazards and cause more widely-spread disasters, which are even more difficult to prevent and can throw the whole society into a panic. Without a set of scientific and effective coping mechanisms and management methods as well as a coping crew with firm beliefs and strong abilities, people will face more troubles in the future (Antoniou \& Cooper, 2017). Thus, it has become the most important and urgent project to improve 
crisis rescuers' resilience and set up a scientific and systematic crisis coping prevention mechanism.

\subsection{The main structures of crisis coping}

At present, crisis coping can be broken down to three aspects: hazard identification, vulnerability analysis, and resilience evaluation (Fan, 2009; Steinebach \& Knill, 2017; Jin, Frasustino, \& Liu, 2016). Hazard identification is the process of judgment, classification, and identification of all kinds of potential and existing crisis events through historical and statistical data collection, research, and analysis to find out the causes to the hazard and qualitatively analyze the outcomes (Fan, 2009; Susanne, 2013). And because unconventional crisis events do not provide enough precursors and are too uncertain to predict the occurrence probability, it is not very effective to adopt the conventional risk evaluation model of "probability multiply with consequence". Among the affected by the crisis, people are the ones with subjective initiatives, so we also need to consider how to control mental vulnerability of both individual and group. Nevertheless, existing mental vulnerability analysis for people is based on how crisis affects its receiving objects, neglecting the fact that people can actively respond, and lack a clear understanding of the people's feedback mechanisms in the event chain of how people will react to crisis events and then how the events will act upon people again such as the phenomenon of "panic to chaos" (Bickman, Lyon, \& Wolptert, 2016). Thereby, we need to explore the mental vulnerability of people with a space-time analysis of "physics-psychology coupling" and realize more systematic analysis of vulnerability of hazard's receiving objects in the situation of unconventional crisis. That is why it is one of the most important and urgent research projects to foster a confident, competent, and powerful coping team, improve crisis coping team members' resilience, and set up a scientific and systematic crisis coping and prevention mechanism.

\subsection{Rescuers’ resilience model}

Research on the model of resilience has a long cultural tradition in China (Fan \& Lu, 2020; Hao, Hong, Xu, Zhou, \& Xie, 2015). It is well known that there is a striking difference between ancient Chinese mythology and Western culture-in Greek mythology, fire was stolen by Prometheus; and in Chinese mythology, fire was made by their perseverance in drilling wood for fire. Our ancestors conquered the flood; if there is a mountain in front of your door, moving is the best choice. In the tribal era, the sun god has absolute authority, only the Chinese mythology has the courage to challenge the sun god, a person because the sun is too hot, go after the sun, want to take off the sun (Kuafu chasing the sun). The Chinese ancestors told their descendants that they could lose but not yield. During the cultural revolution, there were also a series of people ups and downs. Studies of Sichuan earthquake (in 2008) have shown that long after the earthquake, these rescuers kept having mental health problems, which impeded the process of post-earthquake society rebuilding. Furthermore, either disaster sufferers or suffering witnesses could have post-traumatic stress disorder (PSTD). That is why rescuers also need to be "rescued." Presently, rescuers' mental health and its improvement methods has become one of the major problems in disaster psychology and rescuer aid program at home and abroad (Shi, 2013). However, we lack a series of empirical studies to explore the resilience model based on individual level, group level, especially the mechanism of resilience model. Therefore, it is necessary to carry out the model of the resilience of the rescue workers and its training development research.

\section{The Resilience Model Study}

Focusing on crisis event situation, this study explores crisis rescuers and rescuer groups' resilience structure model and their working mechanism and conduct field trials of intervention at where the subjects are used for the model. There are four studies, and their structure relationship is as follows. Firstly, what are the main components of crisis rescuers' resilience model? Can these components accurately reflect the essence of crisis rescuers resilience when coping with crisis situation? Secondly, what are the main components of crisis rescuer teams' resilience model under the specific crisis coping situation? And what are the comparison and contrast of crisis rescuers' and crisis rescuer teams' resilience model? Thirdly, we are going to explore resilience model's mechanism from three routes: the first route is to investigate individual's resilience's influence on their coping method and mental health level from perspective of individual health; the second route is to investigate individual's resilience's influence on risk perception and crisis coping abilities from the point of view of crisis decision-making. The third is to see how group resilience influences individual resilience and their mental health level. Last but not least, based on the findings of the three findings, we will conduct field trials of intervention study in representative organizations and firms. During the intervention study, we firstly need to verify that effectiveness of resilience questionnaire, and then we will design specific intervention mode, and, lastly, to verify the effectiveness of our 
intervention mode and transform our research findings into practice.

\subsection{Exploration individual resilience structure for crisis rescuing member}

We interviewed 20 subjects about their experiences of crisis rescuing event from public security, armed police and military institutes. Combing the three groups' interview results with focus interview data, we had two graduates to encode all these materials and form an initial construct. The subjects are from three institutes from Jinhua in Zhejiang province, Anyang, and Zhengzhou in Henan province. We gave out 600 questionnaires in total and 578 completed ones were returned. Through several explorations, 26 items left in the end and extracted a five-dimension structure of individual's resilience. The naming for the new factor structure is as follows:

(1) Factor one has six items, and its content includes: individuals can keep their emotion less influenced by outside world in face of crisis events so that they can analyze problems reasonably and objectively. Researchers named it as rational coping.

(2) Factor two has five items, and its content includes: individual's personality trait of strongness which makes him or her to be firmly faithful to protect people's lives and properties and to be constantly responsible for his or her duties is called by the research as strong personality.

(3) Factor three has four items and its content includes: one is good at controlling emotion, positively attributes the reasons for what happened, and is optimistic and hold positive expectations about future, which researchers called optimism.

(4) Factor four has six items and its content includes: one has experiences of successful crisis coping, is confidant in their own abilities, and believe that they can handle situations like this excellently, which researchers called self-efficacy.

(5) Factor five has five items and its content includes: one can accept problems, endure through harsh situations peacefully, handle them with flexibility, become even stronger after crisis, and make constructive contributions, which researchers called flexible adaptation.

The already-verified five factor structure of resilience can describe mental characteristics of crisis rescuing members more accurately compared with the former qualitative study's six factor structure, in which the items of the "hopefulness" dimension are compressed, deleted or moved to the "self-efficacy" or "optimism" dimension. Also, from the results of the explorative factor analysis we can know that the five factor structure's cumulative explained variance difference is $67.53 \%$, which proves the five factor structure to be reliable (see Table 1 ).

\subsection{Exploration team-based resilience structure for crisis rescuing member}

Combing the interview results with three groups focus interview $(\mathrm{N}=20)$ and questionnaire for crisis rescuing members' individual resilience $(\mathrm{N}=186)$, there were 16 left and a four factor structure of group resilience model was formed. The naming for the new factor structure is as follows:

(1) Factor one includes: the group has very successful rescuing experiences, believes that the group can set up effective working goals and plans, has the ability to obtain resources, tries as many ways as possible to overcome problems, and achieves working goals. These items reflect that the group agree with the collective goals and have faith in finishing the tasks, which the researchers called collective efficacy.

(2) Factor two includes: the group sees fighting for people's lives and properties as a holy mission and no matter what; they will not give up their positions and put the mission over their own sacrifice. These items embody the group's holding on to the same belief firmly, responsibilities for their own positions, and the determination in the group, which researchers called common belief.

(3) Factor three includes that the group can always see the bright side of the event and see hope in adversity. They are always optimistic about the future. These items reflect that the group is good at attributing things in a positive way and is positive and optimistic about the future. Also the group is full of support for each other, which researchers called emotional support.

(4) Factor four includes that the group is well prepared for long-term and harsh situations, can keep high spirits in face of sufferings, sees obstacles as steps to a better and stronger group. These items show the group's support, collaboration, flexibility, enduringness, peaceful acceptance, and constructive dealing style when problems come along, which researchers named team flexibility.

Based on Chinese crisis management background, this study designed the resilience questionnaire of the crisis rescuing group, which has good reliability and validity and can be used to assess the resilience level and coping ability of the crisis rescuing group. It can also be used to investigate the formation effect of the crisis rescuing group. This provides theoretical basis and measurement tools for the relevant empirical research and training development work of the crisis management team in the future. 
Table 1. The analysis results for crisis rescuing members' resilience questionnaire

\begin{tabular}{|c|c|c|c|c|c|}
\hline Variables & $\begin{array}{c}\text { Factor } \\
1\end{array}$ & $\begin{array}{l}\text { Factor } \\
2\end{array}$ & $\begin{array}{c}\text { Factor } \\
3\end{array}$ & $\begin{array}{c}\text { Factor } \\
4\end{array}$ & $\begin{array}{c}\text { Factor } \\
5\end{array}$ \\
\hline b11. I am good at resolving the pressure and negative emotions during the rescuing process & $0.78^{*}$ & & & & \\
\hline b10. I have a lot of energy to deal with endless difficulties and obstacles & $0.76^{*}$ & & & & \\
\hline b12. I am never worried even in extremely stressful crisis coping situation like this & $0.73^{*}$ & & & & \\
\hline b7. I can always find ways to adjust my emotions quickly in face of abrupt emergencies & $0.72^{*}$ & & & & \\
\hline b8. I can still keep myself calm down when abrupt emergencies happen & $0.69^{*}$ & & & & \\
\hline b9. I prioritize the steps I need to take even when I encounter many difficult problems & $0.68^{*}$ & & & & \\
\hline $\begin{array}{l}\text { b4. I will never give up holding on to my position and responsibilities no matter what hap- } \\
\text { pens in this rescuing mission }\end{array}$ & & $0.77^{*}$ & & & \\
\hline $\begin{array}{l}\text { b1. Rescuing work involves benefits of our nation and people and I feel highly honored to } \\
\text { finish it }\end{array}$ & & $0.76^{*}$ & & & \\
\hline b2. I promise I will do my best to complete the rescuing missions given out to me & & $0.75^{*}$ & & & \\
\hline b5. I am willing to sacrifice my own benefits for completion of the rescuing task & & $0.75^{*}$ & & & \\
\hline b3. I will never give up my principles of behaviors whatever happens in the rescuing work & & $0.50^{*}$ & & & \\
\hline b31. I always see things from a positive point of view in my rescuing missions & & & $0.85^{*}$ & & \\
\hline b30. I usually hold positive expectations for uncertain things in my rescuing missions & & & $0.80^{*}$ & & \\
\hline b32. I am optimistic about the rescuing work in the future & & & $0.79^{*}$ & & \\
\hline $\begin{array}{l}\text { b34. I feel no need to be pessimistic because there is always a bright side of everything in } \\
\text { rescuing missions }\end{array}$ & & & $0.65^{*}$ & & \\
\hline b17. I believe I can give accurate information when I make statements to others & & & & $0.72^{*}$ & \\
\hline b18. I believe that I can set specific goals in my scope of work & & & & $0.64^{*}$ & \\
\hline b15. I believe I make meaningful contributions to my team's rescuing missions & & & & $0.63^{*}$ & \\
\hline b14. I am confident in reporting my work in rescuing at meetings & & & & $0.63^{*}$ & \\
\hline b16. I believe I can finish the tasks given to me by my leaders & & & & $0.55^{*}$ & \\
\hline b24. I can independently deal with what I have to do in the rescuing work & & & & $0.54^{*}$ & \\
\hline b26. I can stand the sufferings from the obstacles and problems in the rescuing work & & & & & $0.59^{*}$ \\
\hline b25. I never feel dismayed no matter how many obstacles I need to overcome & & & & & $0.58^{*}$ \\
\hline b29. I become stronger through coping with problems in rescuing work & & & & & $0.56^{*}$ \\
\hline b28. I see the obstacles in the rescuing work as steps to be a strengthened me & & & & & $0.56^{*}$ \\
\hline b27. I have a hard time recovering from the difficulties I meet in the rescuing work & & & & & $0.53^{*}$ \\
\hline eigenvalue & 11.90 & 1.77 & 1.67 & 1.15 & 1.07 \\
\hline Variance contribution ratio (\%) & 45.77 & 6.82 & 6.43 & 4.41 & 4.10 \\
\hline Cumulative variance contribution ratio (\%) & & 52.59 & 59.02 & 63.43 & 67.53 \\
\hline
\end{tabular}

Note: ${ }^{*}$ represents p value less than 0.05 .

\section{Exploration on the mechanism of the resilience model based on crisis coping}

This part is mainly to explore the internal mechanism of the resilience of crisis rescuers in the context of sudden crisis events. Firstly, we explored the relationship between the resilience of crisis rescuers' coping styles and mental health. Secondly, we explored the impact of crisis rescuers' resilience on risk perception and crisis decision-making. Finally, we explored how the resilience on the group level influences individual's resilience in the crisis events situation.

We distributed 900 questionnaires at five firms in Zhejiang and Henan province, and 860 questionnaires were returned. After all the questionnaires were collected, we checked the validity of the questionnaires first. After we discarded the questionnaires with too many questions uncompleted and not filled out carefully, 836 copies of the valid questionnaires were left.

In this study, the main variables included: resilience, coping style, and mental health. The corresponding 
measurement tools are as follows:

(1) Individual Resilience Questionnaire: using the individual resilience questionnaire for crisis rescuers designed in this study, we employed the Likert 6-point scale to let the participants evaluate themselves (from 6 meaning "strongly agree" to 1 meaning "strongly disagree").

(2) Coping style questionnaire: using the simplified version of coping style questionnaire designed by Carver (1997), which includes two dimensions: positive response and negative response. There are 14 questions in total. The questionnaire was based on the Likert 7-point scale (from 7 meaning "completely apply" to 1 meaning "completelynot apply"). Among them, the topics that describe positive response include: "take action to deal with difficult situations with full attention", "seek emotional support from others", and so on; the topics that describe the negative response include: "tell yourself that this is not true", "blame yourself for that has happened", and so on.

(3) Mental Health Questionnaire: We used the General Health Questionnaire (GHQ-12) written by Goldberg and Williams (1988) with a total of 12 topics, including social function and mental stress. This questionnaire used the Likert 5-point scale (from 5 meaning "completely apply" to 1 meaning "completely not apply"). Example: "I am able to concentrate when I am working", "lose sleep due to worries", and so on. Some of the topics in the mental stress dimension are scored reversely.

(4) Risk perception. The social risk cognition questionnaire [3] was revised according to the context of crisis events in this study and used, including a total of four questions. The questionnaire was used the Likert 5-point scale (from 5 meaning "completely apply” to 1 meaning "completely not apply”). Example: "when a sudden crisis occurs, those scenes are new to me", "when a sudden crisis occurs, I think it cannot be controlled".

(5) Crisis decision-making: the crisis decision-making questionnaire designed by Kunreuther \& Slovic (1996) was used, which used the Likert 5-point scale (from 5 meaning "completely apply" to 1 meaning "completely not apply"). The questionnaire has four questions, including "I am able to make decisive decisions when I encounter a sudden crisis", "I am satisfied with my decision-making process after the crisis event is handled", and so on.

(6) Group Resilience Questionnaire: using the group resilience questionnaire developed by this study for crisis rescue groups, the subjects self-evaluated through the Likert 6-point scale (from 6 meaning "strongly agree” to 1 meaning "strongly disagree").

The results of the study (see Figure 1 ) showed that rational coping has a significantly positive effect on mental stress $(B=0.15, p<0.05)$, and rational coping has a significantly positive effect on negative response $(B=0.33$, $\mathrm{p}<0.05)$. Strong personality has a positive and significant impact on positive response and has a negative impact on negative coping, with their standardized path coefficient being 0.36 and -0.33 respectively. Negative response plays a full mediating role in the relationship between strong personality and mental stress. Meanwhile, negative coping plays a full mediating role in the relationship between strong personality and social function. Optimism has a direct and significant impact on social function $(\mathrm{B}=0.19, \mathrm{p}<0.05)$. There is a significantly positive correlation between optimism and negative response, with their standardized path coefficient being 0.48 , and the negative response plays a partially mediating role between optimism and social function. Flexible adaptation has a significantly positive effect on social function $(B=0.21, \mathrm{p}<0.05)$; flexible adaptation has a significantly negative impact on negative response $(B=-0.25, p<0.05)$ and has no significant correlation with positive response. At the same time, negative response plays a partial mediating role between flexible adaptation and social function. In addition, self-efficacy has a direct and significant impact on mental stress $(B=0.18, p<0.05)$, indicating that the more self-efficient the crisis rescuers are, the less mental stress they perceive, and the more they can maintain mental health.

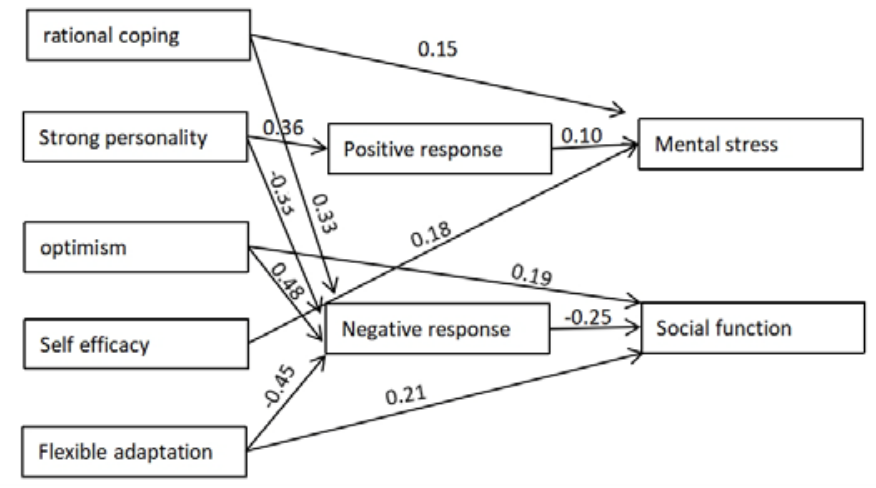

Figure 1. The revised model $(\mathrm{N}=836)$. 
Standardized regression results have shown that the stronger and more rational the crisis rescuers are, it is better for the crisis decision-making, and risk perception has no mediating effect on that (see Figure 2). The more self-efficient the crisis rescuers are, the lower their perception of risk will be, and the higher their crisis decision-making level. This effect is achieved through risk perception. This shows that risk perception has a full mediating effect on confidence levels and crisis decision-making. In addition, the study also adopted a mediation effect test procedure (ie, Sobel test) for verification. The results showed that the mediation effect was significant (Sobel=2.15, $\mathrm{p}<0.05$ ).

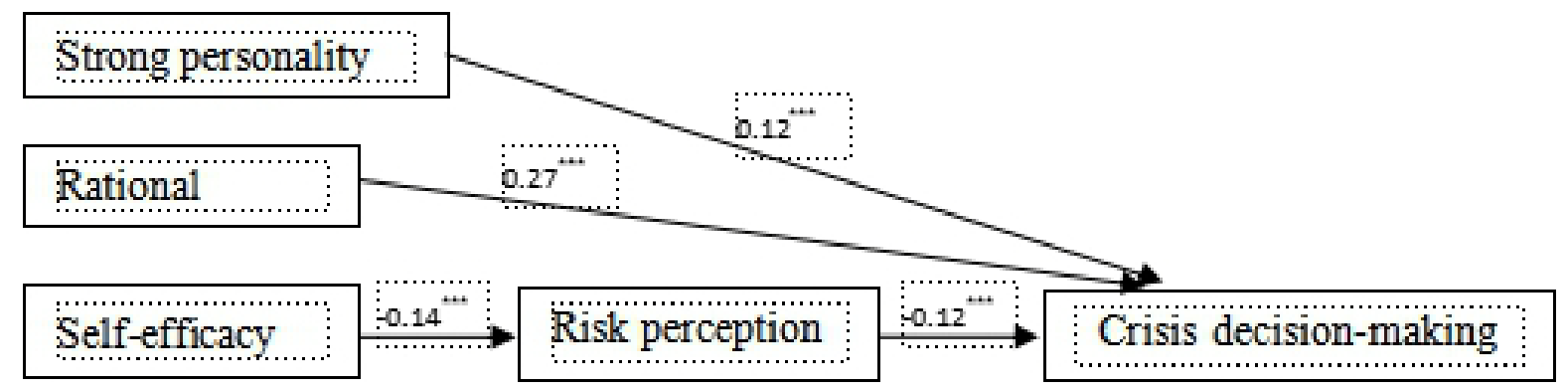

Figure 2. The revised model $(\mathrm{N}=836)$.

Researchers conducted an intermediary regression analysis on the relationship between the three and found that the group resilience has a positive impact on individual resilience. Group resilience further affects individual mental health by affecting the individual resilience. That is, individual resilience has a complete mediating effect between group resilience and individual mental health (see Figure 3).

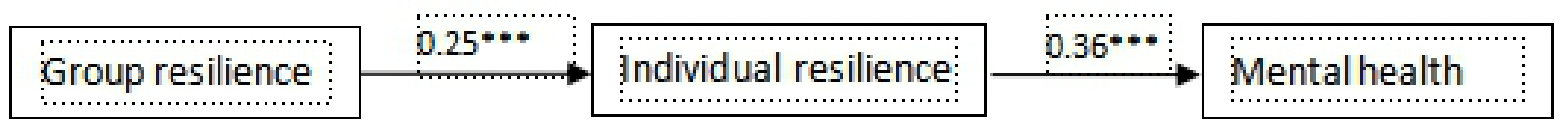

Figure 3. The revised model $(\mathrm{N}=836)$.

\section{Intervention study on resilience model based on crisis coping}

\subsection{Strategic design of training contents}

In order to further verify the effectiveness of the resilience model of crisis rescuers and conduct in-depth intervention research, this study selects coal mine enterprises with frequent crisis events to conduct on-site research (see Figure 4). Firstly, through behavioral event interviews and questionnaire surveys, we will deeply understand the current crisis management status and mental health level of crisis rescuers in coal mines and verify the structural validity of the resilience questionnaire. Secondly, based on the actual background and development needs of coal mine enterprises, we are going to design targeted training intervention models that help rescuers to cope with crisis events and improve their resilience, and explore new training methods. Finally, we will verify the effectiveness of training models in improving crisis rescuers' resilience and mental health level through on-site experiments in order to connect with the national emergency-coping platform.

\subsection{Safety mentality mode training method}

We selected Liangbaosi Company, a leading enterprise in the domestic coal mining industry, as the research subject and tried to explore the training intervention model suitable for coal mine enterprises on how to prevent and cope with crisis from the perspective of the construction of innovative enterprise safety culture system. The main purpose is to improve the resilience of safety supervisors and shape the safety mentality model of all employees for the ultimate goal: to ensure safe production.

Based on the analysis above, we have established seven steps in the training of safety mentality models, and completed designing the "Safety Mentality" training course for conducting training experiments with verification on senior managers, district captains, safety supervisors, and rule-breaking employees. The pilot results basically verified the feasibility of the safety mentality model training method [4]. 


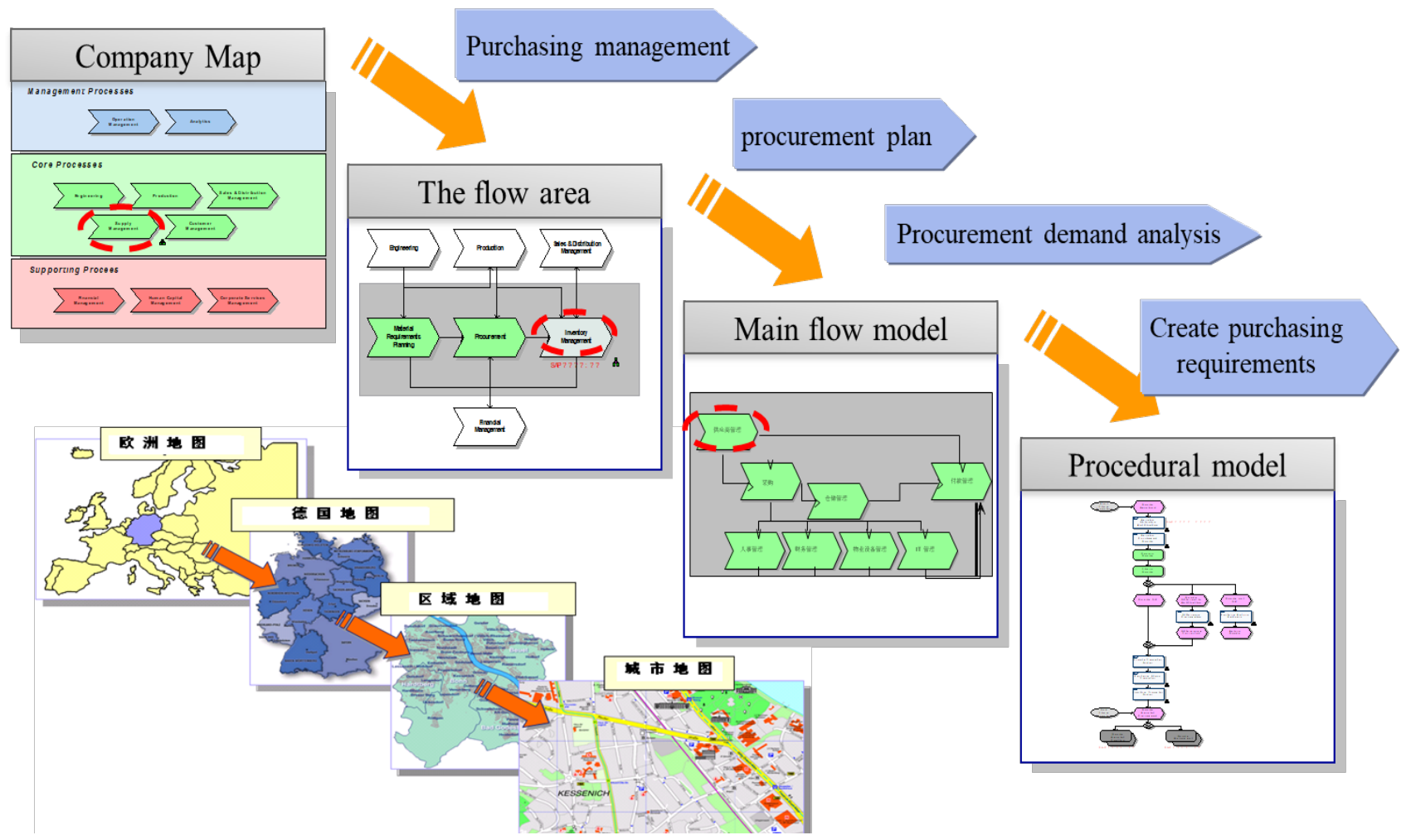

Figure 4. Strategic design of training contents.

\subsubsection{Content of the safety mentality model}

Generally speaking, the mentality model contains three elements: emotion, cognition, and attitude. The safety mentality model advocates the harmonious unification of the body, mind, and spirit in the process of safe production. The Safety Mentality Model training method implements the change and remodeling of the trainee's mentality model through seven gradually-deepening steps, focusing on improving the resilience of the trainees and ensuring safe production. The implementation content of each link is shown in Figure 5.

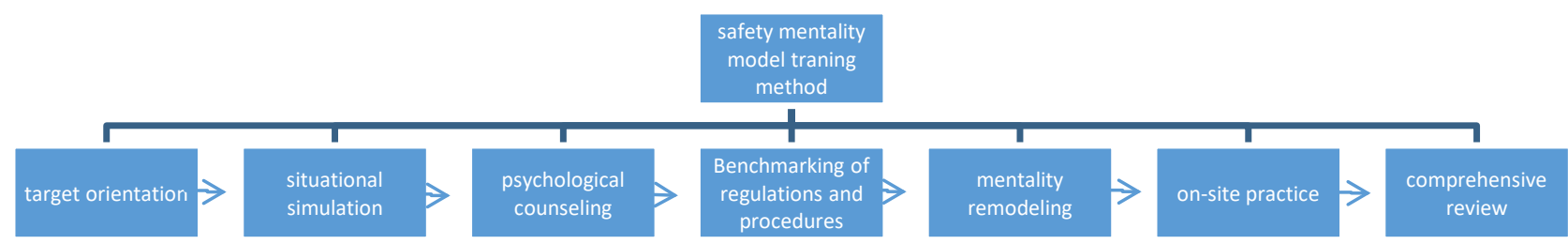

Figure 5. Safety mentality model training framework.

\subsubsection{The logical relationship between the links}

Safety mentality model training is a course developed based on the research foundation of the resilience structure of the crisis rescuers and its internal working mechanism model. It helps to realize the reshaping of the trainee's mental model through seven gradually-deepening teaching sessions with focuses on proving their resilience. The logical relationship between each link is as follows:

A. Target orientation is used to assess the employee's safety mentality model and resilience level, identify the disparity between those and the normal levels, and clarify the training objectives.

B. Situational simulation and psychological counseling, in the safe mental model, respectively realize the 
transformation of physiological characteristics and emotional experience to a safer behavior patterns from two, which is positive and negative, aspects: situational simulation mainly touches trainees' psychological defense from the negative effects of violations of rules; while psychological counseling mainly, from the perspective of positive psychology, enlightens the trainees' psychological experience, changes their attitudes, awakens their responsibility for safety, and enhances their level of resilience in response to crisis events. The research basis is derived from the Study 3, which is about the relationship between individual resilience, coping style, and mental health.

C. Benchmarking of regulations and procedures and mentality remodeling mainly reflect the acquisition, change or remodeling of safety mentality models from the perspective of risk perception and decision-making models: Benchmarking of regulations and procedures aim to integrate safety production related professional knowledge and defense skills against the common violations of rules in safety management and lay down the foundation for the later risk identification and its coping; while mentality remodeling focuses on cultivating students' knowledge for recognizing various risk sources and coping and mentality skills to improve their resilience in risk coping. The research is based on the Study 3, which is about relationship between individual resilience, risk perception, and crisis decision-making.

D. At the final stage of on-site practice and comprehensive review, the former realizes attitudes, responsibilities, and values' migration to reality and its solidification - in other words, it reshapes, consolidates, and distillates the mental models on individual's, group's and organization's management levels. And comprehensive review assesses whether the safety mentality model training has achieved its goal and whether the ultimate goal of the establishing safety culture in coal mine enterprises is achieved after practice.

\subsection{Design of comparative training experiment}

\subsubsection{Research framework}

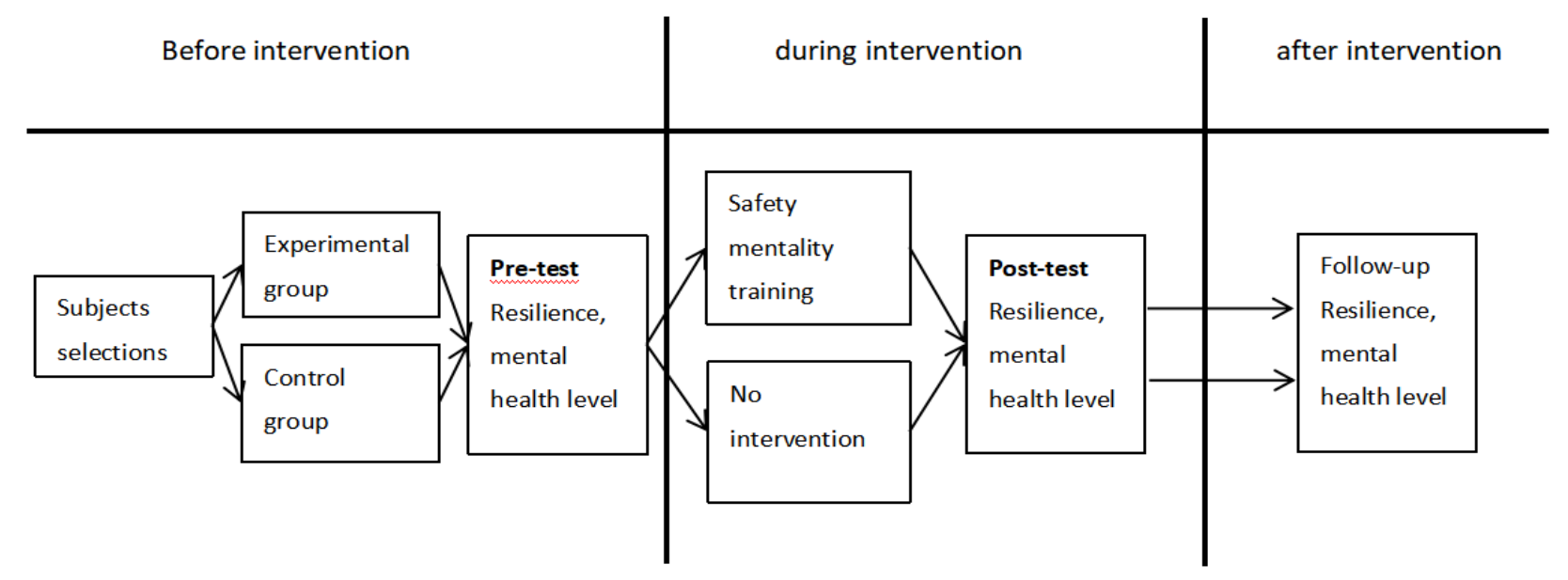

Figure 6. The framework for the comparative study.

The specific hypotheses of this study are as follows (see Figure 6):

Hypothesis 1: After the implementation of the "Safety Mentality Model Training" intervention based on the resilience model, the post-test results of the mental health level, resilience, and coping behavior of the rescuers were significantly higher than those of the previous test;

Hypothesis 2: After two months of intervention, the scores of mental health, resilience, and coping behavior of rescuers were still significantly higher than the previous test.

\subsubsection{Participants}

Experimental group: 36 people. The basic information of the participants was as follows: males: $75 \%$, females: 25\%; (age) 30 and under: 28\%, 31-40: 28\%, 41-50: 39\%, over 50: 6\%; those who have college education and below: $52 \%$, undergraduates: $37 \%$, postgraduates: $11 \%$; those who work underground: $38 \%$, on the ground: $48 \%$, security and other positions: 14\%; ordinary employees: 40\%, first line managers (group leaders): 28\%, middle managers (district captains): 32\%; working for less than 5 years: 28\%, working for 5 to 15 years: 17\%, working for 15 years or more: $53 \%$. 
Control group: 40 people. The basic information of the participants was as follows: males: $65 \%$, females: $35 \%$; (age) 30 and under: 44\%, 30-39: 36\%, 41-49: 17\%, over 50: 3\%; those who have high school/technical school education and below: $45 \%$, some college education: $28 \%$ undergraduates: $27 \%$; those who work underground: $37 \%$, on the ground:57\%, other positions: $6 \%$; ordinary employees: $55 \%$, first line managers (group leaders): $22 \%$,middle managers (district captains): 23\%; working for less than 5 years: 14\%, working for 5 to 15 years: 45\%, working for 15 years or more: $41.5 \%$.

\subsubsection{Measures}

A. Individual resilience: using data-proven self-made resilience questionnaire.

B. Coping behavior: using the simplified coping style questionnaire designed by Carver (1997).

C. Mental health: using the General Health Questionnaire (GHQ-12) prepared by Goldberg \& Williams (1988).

\subsubsection{Procedures}

The survey was completed in three sessions, the first time before the training, the second time at the end of the training, and the third time two months after the end of the training. In the first survey, the researchers were present to answer individual questions and informed the participants that the results were confidential and they would only be used to provide a research basis for improving the quality of training and management methods for enterprises. In the second survey, the researchers also were present to answer questions and ensured the quality of the questionnaires. In the third survey, the researcher entrusted and trained the person in charge of the training in the company to complete the survey. All the questionnaires from the two previous surveys were collected on the spot, and for the third time, because some of the participants were not on site, the questionnaire collection was completed by fax.

\subsection{Results of comparative training experiment}

\section{A. Difference test of resilience variables}

We carried out t-test for the data of experimental group and the control group before training, after training, and their follow-up survey. It can be seen from Table 2 that before the training, the experimental group and the control group did not have significant differences in all dimensions of the resilience. After the training, the scores of the experimental group's resilience and its components like rational response, self-efficacy, and optimism were significantly higher than those in the control group; the results of two months after the training showed that the experimental group's scores for resilience and those three dimensions were still significantly higher than that of the control group, but its significance level decreased (from $\mathrm{p}=0.038$ to $\mathrm{p}=0.042$, from $\mathrm{p}=0.034$ to $\mathrm{p}=0.042$, from $\mathrm{p}=0.028$ to $\mathrm{p}=0.035$, and from $\mathrm{p}=0.039$ rose to $\mathrm{p}=0.044$ respectively). The post-test results showed that the scores after the training and that after two months for resilience and its three dimensions were significantly higher than before the training, and there is no significant difference between the tracking results (two months after the training) and the post-training results. All of the results above show that the effect of training is significant in the psychological variable of resilience, and the effect of training can last for two months or even longer.

The t-test of pre-training, post-training and follow-up measurement was carried out for the experimental group and the control group, and it can be seen from Table 2 that there was no significant difference between the experimental group and the control group in the positive response and the negative response before the training. After the training, the score of the experimental group on the positive response was significantly higher than that of the control group, and the score on the negative response was significantly lower than that of the control group; the tracking measurement (after two months) showed that the scores of the experimental group in both dimensions were still in that trend, but its level of significance decreased (from $\mathrm{p}=0.028$ to $\mathrm{p}=0.030$ and from $\mathrm{p}=0.018$ to $\mathrm{p}=0.023$, respectively). In addition, the analysis results of repeated measured variance also showed that there were significant differences in the scores of the two dimensions of the experimental group. The results of the post-test showed that the scores of negative response from the tracking survey and the survey after training were significantly lower than the pre-training data, while the positive response scores were significantly higher than the pre-training results, and there was no significant difference between the tracking results and the post-training results. All of the results above show that the effect of training is significant in the variable of coping style. 
Table 2. The difference test between experimental and control group on resilience

\begin{tabular}{|c|c|c|c|c|c|c|c|}
\hline & & \multicolumn{2}{|c|}{ Before training } & \multicolumn{2}{|c|}{ After training } & \multicolumn{2}{|c|}{ Follow-up } \\
\hline & & Control & experiment & control & experiment & control & experiment \\
\hline \multirow{4}{*}{$\begin{array}{l}\text { Strong perso- } \\
\text { nality }\end{array}$} & Number of subjects & 40 & 35 & 40 & 34 & 39 & 35 \\
\hline & mean & 4.25 & 4.35 & 4.28 & 4.44 & 4.26 & 4.37 \\
\hline & Standard deviation & 1.02 & 0.89 & 0.77 & 0.68 & 1.21 & 0.99 \\
\hline & $\mathrm{p}$ values & 0.470 & & 0.560 & & 0.490 & \\
\hline \multirow{4}{*}{ Rational coping } & Number of subjects & 40 & 35 & 40 & 35 & 39 & 35 \\
\hline & mean & 4.80 & 4.78 & 4.89 & 5.35 & 4.86 & 5.29 \\
\hline & Standard deviation & 0.87 & 0.97 & 0.58 & 1.01 & 0.90 & 0.47 \\
\hline & $\mathrm{p}$ values & 0.340 & & $0.034^{*}$ & & $0.042^{*}$ & \\
\hline \multirow{4}{*}{ Self-efficacy } & Number of subjects & 40 & 34 & 40 & 35 & 40 & 34 \\
\hline & Mean & 4.92 & 4.98 & 4.96 & 5.42 & 4.89 & 5.46 \\
\hline & Standard deviation & 0.67 & 0.89 & 1.12 & 0.56 & 0.87 & 0.79 \\
\hline & $\mathrm{p}$ values & 0.560 & & $0.028^{*}$ & & $0.035^{*}$ & \\
\hline \multirow{5}{*}{$\begin{array}{l}\text { Flexible adapta- } \\
\text { tion }\end{array}$} & Number of subjects & 38 & 35 & 39 & 34 & 39 & 34 \\
\hline & mean & 4.31 & 4.28 & 4.35 & 4.39 & 4.28 & 4.37 \\
\hline & Standard deviation & 1.05 & 0.89 & 1.08 & 0.83 & 0.67 & 0.69 \\
\hline & $\mathrm{p}$ values & 0.450 & & 0.560 & & 0.490 & \\
\hline & Number of subjects & 40 & 35 & 39 & 35 & 40 & 34 \\
\hline \multirow{3}{*}{ Optimism } & mean & 4.88 & 4.79 & 4.78 & 5.25 & 4.82 & 5.27 \\
\hline & Standard deviation & 0.76 & 0.80 & 0.77 & 0.69 & 1.05 & 0.78 \\
\hline & $\mathrm{p}$ values & 0.670 & & $0.039^{*}$ & & $0.044^{*}$ & \\
\hline \multirow{4}{*}{ Resilience } & Number of subjects & 38 & 34 & 39 & 34 & 39 & 34 \\
\hline & mean & 4.78 & 4.82 & 4.80 & 5.18 & 4.82 & 5.12 \\
\hline & Standard deviation & 0.87 & 0.68 & 0.96 & 1.07 & 0.92 & 0.89 \\
\hline & p values & 0.480 & & $0.038^{*}$ & & $0.042^{*}$ & \\
\hline
\end{tabular}

Note: ${ }^{*}$ represents p value less than 0.05 .

\section{B. Difference test of mental health variables}

The t-test of pre-training, post-training and follow-up measurement was carried out for the experimental group and the control group. It can be seen from Table 3 that there was no significant difference in mental stress and social function between the experimental group and the control group before the training. After the training, the scores of the experimental group on mental stress were significantly lower than that of the control group. The follow-up results after two months showed that the scores of the experimental group on mental stress were still significantly lower than the control group, but their significance level decreased (from $p=0.032$ to $p=0.041$ ); there was no significant difference in the scores of social function before the training, after the training, and during the follow-up survey. At the same time, the results of repeated measured analysis of variance also showed that there were significant differences in the scores of mental stress in the experimental group across three surveys. The results of post-test showed that the scores on the mental stress of the follow-up survey and post-training were significantly lower than the pre-training data, and there were no significant differences between the results of follow-up and post-training survey. All the results above show that the effect of training is significant in the variable of perception mental stress, and that trainee can cope with the stress properly, so that the perceived stress intensity is reduced. The training effect can last for two months or even longer. In addition, there is no significant difference in social function across the three surveys and between the two groups. Perhaps this is related to 
objective factors that nation-owned coal mine employees have highly stable jobs, less perceived pressure, and relatively normal social function.

Table 3. The difference test on mental health of experimental and control group

\begin{tabular}{|c|c|c|c|c|c|c|c|}
\hline & & \multicolumn{2}{|c|}{ Before training } & \multicolumn{2}{|c|}{ After training } & \multicolumn{2}{|c|}{ Follow-up } \\
\hline & & $\begin{array}{l}\text { Control } \\
\text { group }\end{array}$ & $\begin{array}{c}\text { Experi- } \\
\text { mental } \\
\text { group }\end{array}$ & $\begin{array}{l}\text { Control } \\
\text { group }\end{array}$ & $\begin{array}{c}\text { Experi- } \\
\text { mental } \\
\text { group }\end{array}$ & $\begin{array}{l}\text { Control } \\
\text { group }\end{array}$ & $\begin{array}{l}\text { Experimental } \\
\text { group }\end{array}$ \\
\hline & Number of subjects & 40 & 35 & 39 & 34 & 38 & 34 \\
\hline \multirow[t]{3}{*}{ Mental stress } & mean & 2.80 & 2.89 & 2.87 & 2.53 & 2.85 & 2.51 \\
\hline & Standard deviation & 0.87 & 0.78 & 0.69 & 0.72 & 0.59 & 0.71 \\
\hline & $\mathrm{p}$ values & 0.570 & & $0.032^{*}$ & & $0.041^{*}$ & \\
\hline \multirow[t]{4}{*}{ Social function } & Number of subjects & 40 & 35 & 40 & 34 & 39 & 34 \\
\hline & mean & 4.11 & 4.08 & 4.07 & 4.13 & 4.09 & 4.15 \\
\hline & Standard deviations & 0.90 & 0.89 & 0.77 & 0.69 & 0.84 & 0.72 \\
\hline & $\mathrm{p}$ values & 0.490 & & 0.520 & & 0.570 & \\
\hline
\end{tabular}

Note: ${ }^{*}$ represents p value less than 0.05 .

\section{Conclusions}

In this series of studies, we paid our attention to how resilience affects employees' work attitude, work behavior, and job performance, especially influence of self-adjustment methods, including emotional labor strategies, and dissociation, and the relationship between resilience, positive emotion, self-adjustment method, and job performance. In addition, this study looked into how variables on the group level have influenced the individual and group's resilience, how group resilience and group's positive atmosphere have influence individual's resilience, and individual and group resilience's have influence on work outcomes. Finally, we explored how to train people for better resilience and see if resilience improvement can boost their positive emotions, adaptive behaviors, and coping abilities, which is more valued in reality. In all, we combined empirical study and qualitative research to reveal how rescuers' psychological reactions and behaviors work in unconventional crisis situation. The conclusions of the present study as following:

First of all, the resilience of rescuers based on sudden crisis situations is a five-factor structure, including: rational coping, strong personality, optimism, self-efficacy, and flexible adaptation. The resilience of the crisis rescue group is a four-factor structure, including: collective efficacy, common beliefs, emotional support, and team flexibility.

Secondly, the resilience questionnaires of crisis rescuers and rescue group based on China's emergency-coping situation and cultural background have good reliability and validity, which not only lay a theoretical foundation for future research on crisis management, but also provide measurement tools for the recruiting and training of rescuers.

Thirdly, the coping style plays a mediating role between resilience and mental health. Among them, positive coping plays a full mediating effect between strong personality and mental stress. Negative coping plays a full mediating effect between strong personality and social function and between rational coping and social function. The institute with high level of group resilience has members with high level of resilience and mental health, and the individual resilience mediates between the group resilience and individual mental health.

Last but not least, the results of on-site experimental research show that the "Safety Mentality Training" course created based on the safety mentality model training method developed by China's coal mine enterprises is effective for improving the resilience and mental health of crisis rescuers.

\section{Funding}

This study is funded by the Project of National Social Science Foundation (19FGLA002). 


\section{References}

Antoniou, A. S., \& Cooper, C. L. (2017). Coping, personality and the workplace: Responding to psychological crisis and critical events. Routledge.

Bickman, L., Lyon, A. R., \& Wolptert, M. (2016). Achieving precision mental health through effective assessment, monitoring, and feedback processes.

Bonanno, G. A. (2004). Loss, trauma and human resilience: Have we underestimated the human capacity to thrive after extremely aversive events? American Psychologist, 59(1), 20-28.

Carver, C. S. (1997). You want to measure coping but your protocol' too long: Consider the brief cope. International Journal of Behavioral Medicine, 4(1), 92-100.

Connor, K. M., \& Davidson, J. R. T. (2003). Development of a new resilience scale: The Connor-Davidson resilience scale (CD-RISC). Depression and Anxiety, 18(2), 76-82.

Cynthia, S., \& Jacelon, M. S. (1997). The trait and process of resilience. Journal of Advanced Nursing, 25(1), 123-129.

Fan, W., Liu, Y., \&Weng W. (2009). Triangular Framework and “4+1” Methodology for Public Security Science and Technology. Science \& Technology Review, 27(6):3-13.

Fan, X. Y., \& Lu, M. (2020). Testing the effect of perceived social support on left-behind children's mental well-being in mainland China: The mediation role of resilience. Children and Youth Services Review, 109, 104695.

Hao, S., Hong, W., Xu, H., Zhou, L., \& Xie, Z. (2015). Relationship between resilience, stress and burnout among civil servants in Beijing, China: mediating and moderating effect analysis. Personality Individual Differences, 83, 65-71.

Golderberg, D., \& Williams, P. (1996). A user's guide to the general health questionnaire. Windsor, UK: NFER-Nelson, Kunreuther, H., Slovic, P., Science. The Annals of the American Academy of Political and Social Science, 545, 116-125.

Jin, X. C., Qu, M. Y., \&Bao, J. G. (2019). Impact of crisis events on Chinese outbound tourist flow: A framework for post-events growth. Tourism Management, 74: 334-344.

Jin, Y., Frasustino, J. D., \& Liu, B. F. (2016). The scared, the outraged, and the anxious: How crisis emotions, involvement, and demographics predict publics' conative coping. International Journal of Strategic Communication, 10(4): 289-308.

Luthans, F., Avey, J. B., \& Avolio, B. J. (2006). Psychological capital development: Toward a micro-intervention. Journal of Organizational Behavior, 27, 387-393.

Polk, L. V. (2000). Development and validation of the Polk Resilience Patterns Scale. A dissertation submitted to the Faculty of the school of the nursing of the Catholic University of America. Washington, D.C.

Shi, K. (2013). Rescuers' resilience model in response to unusual emergencies, Science Press. (in Chinese)

Siu, O. L. (2005). Ways of Coping with Workplace Stress in Hong Kong and Beijing. Peking U Business Review, 10(5), $62-66$.

Steinebach, Y., \& Knill, C. (2017). Social policy in hard times: Crisis-coping strategies in Europe from 1976 to 2013. International Journal of Public Administration, 40(14): 1164-1174.

Susanne, B. (2013). Workplace hazard identification and management: The case of an underground mining operation. Safety Science, 57: 129-137.

Wagnild, G. M., \& Young, H. M. (1993). Development and psychometric evaluation of the Resilience Scale. Journal of Nursing Measurement, 1(2), 165-178.

Williams, T. A., Gruber, D. A., Sutcliffe, K. M., Shepherd, D. A., \& Zhao, E. Y. (2017). Organizational response to adversity: fusing crisis management and resilience research streams. The Academy of Management Annals, 11(2), 733-769.

Zheng, R., \& Shi, K. (2008). Factors and mechanisms of public social risk cognition. (in Chinese)

Zhu, L., Zhang, B., \& Shi, K. (2013). Safety mind training, China Labor and Social Security Press. (in Chinese) 